\title{
Macroscopic and microscopic analysis of friction stir welding of polyethylene
}

\author{
Daniela-Monica IORDACHE ${ }^{1, *}$, Eduard-Laurenţiu NIŢU ${ }^{1}$, Lia BOŢILA $\breve{2}^{2}$ \\ ${ }^{1}$ University of Pitești, Pitesti \\ ${ }^{2}$ National Institute for Welding and Material Testing ISIM, Timişoara \\ *Corresponding author e-mail: monica.iordache@upit.ro
}

Article history

Received 15.05.2020

Accepted 20.06.2020

DOI https://doi.org/10.26825/bup.ar.2020.006

\begin{abstract}
The automotive industry is one of the most dynamic, advanced and innovative industries in Europe, being in constant search of solutions to reduce fuel consumption and pollutant emissions while maintaining or even improving the safety of passengers. One of the main directions in which the research of all car manufacturers is focused to reduce the weight of the car, through the increasing use of light metal alloys and polymeric materials. Polyethylene is one of the most widely used polymeric materials in the world, being widespread in many industries. The increasing use of this category of materials has led to the need to develop new reliable and efficient techniques for joining different materials to be used in complex structures. In the aeronautical and aerospace field, polymeric materials are used due to their low weight. The paper presents the macroscopic and microscopic analysis of the joining of these materials by FSW.
\end{abstract}

Keywords: polyethylene, friction stir welding, automotive

\section{Introduction}

The use of polymeric materials in the automotive industry is becoming more common, with each passing day. In most cases, these components are mechanically fixed or glued. Both joining processes are expensive, both in terms of processing materials to obtain a suitable geometry, and in terms of labor and time consumed to achieve joints soldering. The solution of their welding by friction stir welding is very new and is approached in the specialized literature, as a research subject, only for certain materials [1], [2], [3].

FSW welding is a purely mechanical solid state joining process, which is based on the frictional heating of the materials to be welded, performed at the interaction between non-consumable welding tools, which rotates on the contact surfaces of the joint [3], [4], [5], [6].

During welding, the pin moves in the material, while the shoulder rotates along the surface. The heat is generated by the friction between the tool shoulder on the surface of the material, and also due to the friction of the pin in the material. This mixing action allows the material to be transferred along the welding line so that the welding can be performed without melting the material. The welding tool is moved at the welding speed along the joint line. The material is transferred behind the tool, creating a welded join.

The maximum temperature reached in the components is approximately 0.8 of the melting temperature. Unlike conventional friction welding, the FSW process is superimposed on a heating effect on a mechanical effect, mixing the welded materials. 
The workpieces are first fixed with a device specially designed for this type of process. Next, the shoulder and the pin begin to rotate in the same direction. The shoulder (figure 1B) presses on the upper part of the joints and thus generates heat by friction.
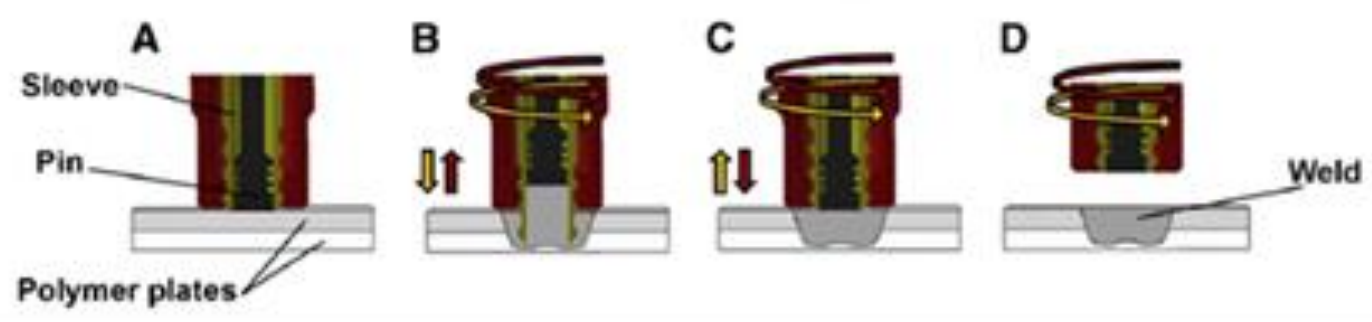

Figure 1. Schematic view of FSW [2]

When the desired depth is reached, the shoulder and pin are returned to their original position (figure 1C), pushing the soft polymer into the cavity to fill the gap left behind by the pin. At the end of welding, the tool is retracted and the joint is consolidated under pressure, in order to avoid thermal contraction (figure 1D) [2].

\section{Experimental procedure}

A high-density black polyethylene was used for pressure pipes, PE 80, which belongs to the category: polymers - thermoplastic - polyethylene - HDPE / pipes. Borstar produces the PE 80 material - highdensity black polyethylene with an advanced technology. The well-dispersed carbon provides outstanding UV resistance, with long-term stability ensured by an optimized stabilization system.

High-density polyethylene is recommended for pressure pipe systems with application areas such as drinking water and natural gas, sewers, drains, other industrial applications. It is specially designed for the production of pipes with large diameters and wall thicknesses, but can be made for all types of diameters. It also has excellent resistance to crack propagation. The properties of this material are presented in table 1.

Table 1. Material properties

\begin{tabular}{|c|c|c|c|l|l|c|c|}
\hline Density & $\begin{array}{c}\text { Carbon } \\
\text { black }\end{array}$ & Hardness & $\begin{array}{c}\text { Tensile } \\
\text { strength }\end{array}$ & Elongation & Resilience & $\begin{array}{c}\text { Fragility } \\
\text { temperature }\end{array}$ & $\begin{array}{c}\text { Melting } \\
\text { temp. }\end{array}$ \\
\hline $\begin{array}{c}0.950 \mathrm{~g} / \mathrm{cm}^{3}- \\
0.960 \mathrm{~g} / \mathrm{cm}^{3}\end{array}$ & $2 \%$ & $\begin{array}{c}60 \text { Shore } \\
\text { hardness } \\
\text { tester }\end{array}$ & $\begin{array}{c}24.99 \\
\mathrm{MPa}\end{array}$ & $>600 \%$ & $1.60 \mathrm{~J} / \mathrm{cm}^{2}$ & $-70^{\circ} \mathrm{C}$ & $\begin{array}{c}200- \\
220^{\circ} \mathrm{C}\end{array}$ \\
\hline
\end{tabular}

Black polyethylene plates $2 \mathrm{~mm}$ and $5 \mathrm{~mm}$ thick were joined using a tool made of X40CrMoV5 material, with a conical pin $4.8 \mathrm{~mm}$ long, the diameter tool shoulder are $\varnothing 22 \mathrm{~mm}$.

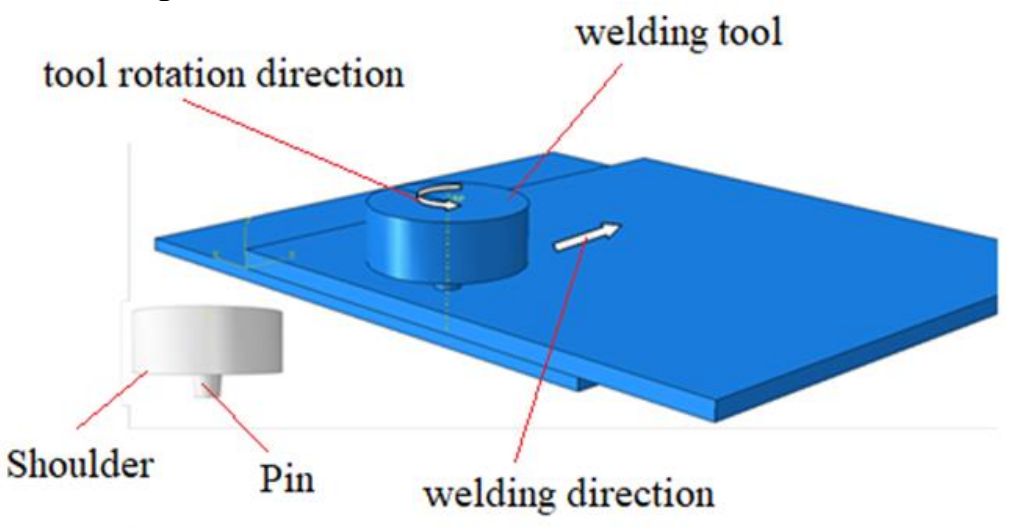

Figure 2. Schematic view of FSW 
At the beginning of the welding process, the welding speed of $20 \mathrm{~mm} / \mathrm{min}$ and $30 \mathrm{~mm} / \mathrm{min}$, respectively, was used and then it was increased (after the first half of the welding length) to the value of $40 \mathrm{~mm} /$ min. After a of the welding length, the speed value was increased to $50 \mathrm{~mm} / \mathrm{min}$. A welding tool speed of $1450 \mathrm{rpm}$ was used, the direction of rotation of the tool being counterclockwise.

Black and yellow polyethylene plates, $2 \mathrm{~mm}$ and $3.5 \mathrm{~mm}$ thick, were joined using a tool made of $\mathrm{X} 40 \mathrm{CrMoV} 5$ material, with a $4 \mathrm{~mm}$ long M6 threaded cylindrical pin, the tool shoulder being smooth with a diameter of $\varnothing 16 \mathrm{~mm}$.

A welding tool speed of $1450 \mathrm{rpm}$, welding speeds of $20 \mathrm{~mm} / \mathrm{min}, 30 \mathrm{~mm} / \mathrm{min}$ and $40 \mathrm{~mm} / \mathrm{min}$ were used.

\section{Results and disscusion}

Welded joints were visually inspected for defects in external morphology and cross sections. The upper surface macrograph of the FSW joints of black polyethylene is shown in Figure 3, and the macrostructure of the cross section is shown in Figure 4.

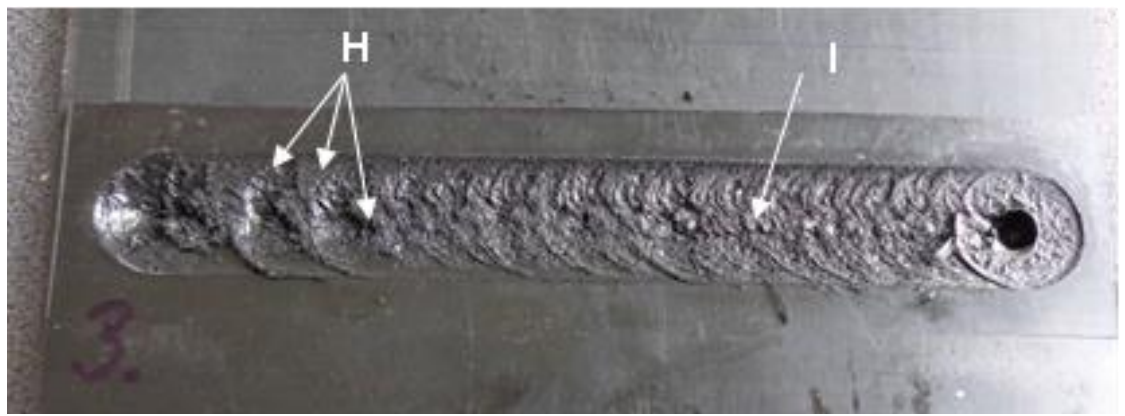

Figure 3. The visual aspect of FSW joint of blackpolyethylene

It is observed that when using lower welding speeds $(20-30 \mathrm{~mm} / \mathrm{min})$, there is a tendency for bumps to occur, but their location is lower than in previous experiments (area $\mathrm{H}$ - figure 3 ). Starting with the use of higher welding speeds $(40-60 \mathrm{~mm} / \mathrm{min})$, the welding has a more uniform appearance, the welding process being more stable (zone I - figure 4 ).

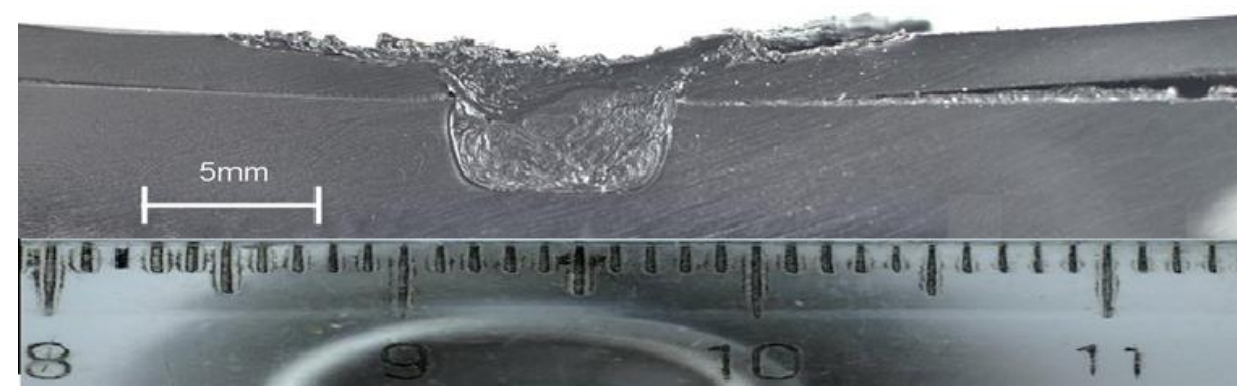

Figure 4. Macrostructure of the transverse cross section of black polyethylene welded joint

The joint formation mode is characteristic of the FSW welding process. When using the speed $\mathrm{v}_{1}=30$ $\mathrm{mm} / \mathrm{min}$ no major pore defects are observed, Figure 4 . The joint adhered well to the materials to be welded, on the advance side of the welding tool, but on the retracting side of the welding tool there is a lack of fusion between it and the material plate located below.

On microscopic analysis several areas of the joint were investigated by the SEM technique, Figure 5.

The morphological analysis of the areas presented in Figure 5 highlights the fact that the joint area has an irregular shape (the contour of the joint area is easily highlighted ) and the existence of several "void" type defects. 


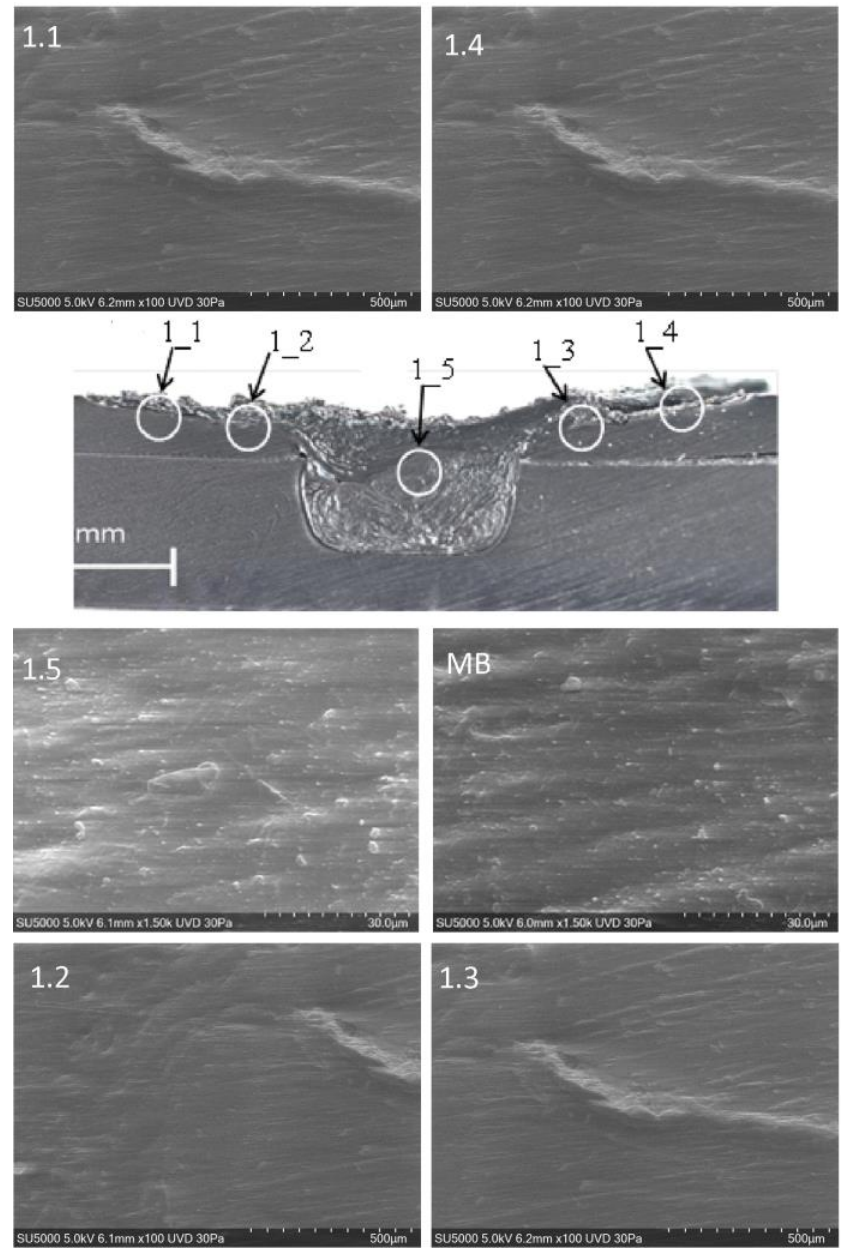

Figure 5. Microstructure at different locations of joint black polyethylene

Black and yellow polyethylene plates, $2 \mathrm{~mm}$ and $3.5 \mathrm{~mm}$ thick, were combined using a welding tool speed of $1450 \mathrm{rpm}$, welding speeds of $20 \mathrm{~mm} / \mathrm{min}$ (area N, figure 6), 30mm / min (zone O, Figure 6), respectively $40 \mathrm{~mm} / \mathrm{min}$ (zone M, Figure 6).

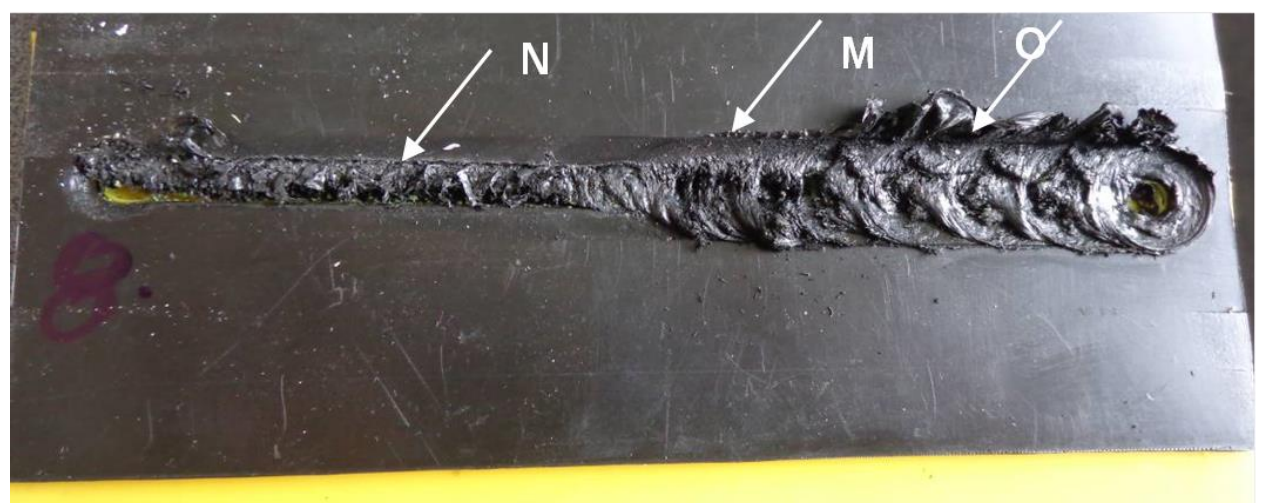

Figure 6. The visual appearance of the FSW joint in black and yellow polyethylene

When using the speed of $40 \mathrm{~mm} / \mathrm{min}$, an attempt was made to achieve the welded joint without pressing the tool shoulder on the materials to be welded. The purpose of the tool shoulder was only to keep the plasticized material in the joint area. At speeds of $20 \mathrm{~mm} / \mathrm{min}$ and $30 \mathrm{~mm} / \mathrm{min}$, respectively, a force was 
applied to the shoulder of the tool on the material to be welded, this contributing to the plasticization of the material placed above. The detailed appearance of the sample corresponding to zone $\mathrm{N}$ is shown in Figure 7. The macroscopic aspect of the welded joint in zone $\mathrm{O}$ is presented in Figure 8.

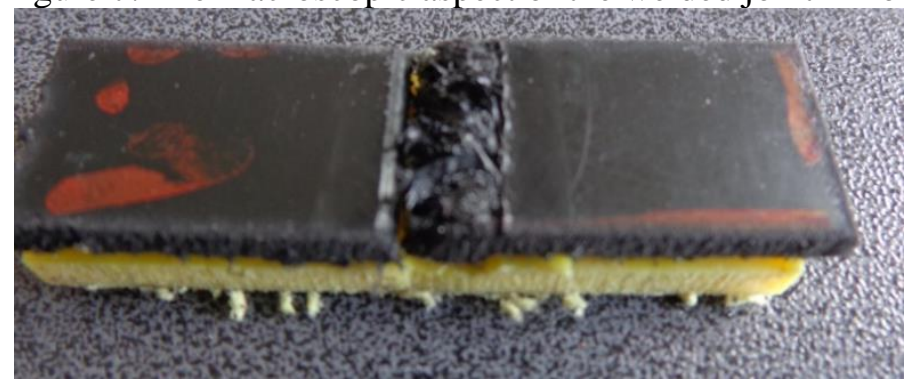

Figure 7. Aspect of the sample corresponding to zone N, vs $=40 \mathrm{~mm} / \mathrm{min}$

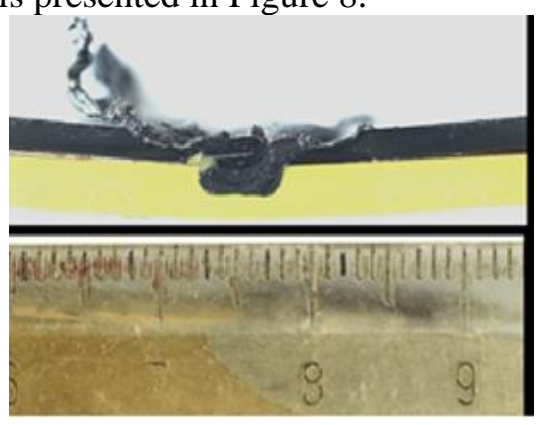

Figure 8. Macroscopic aspect of the joint - zone $\mathrm{O}$, vs $=20 \mathrm{~mm} / \mathrm{min}$

The chips formed at the lower tool speed were discontinuous and at the higher rotation speed, the polyethylene was found to be overheated and melted, so the chips did not form.
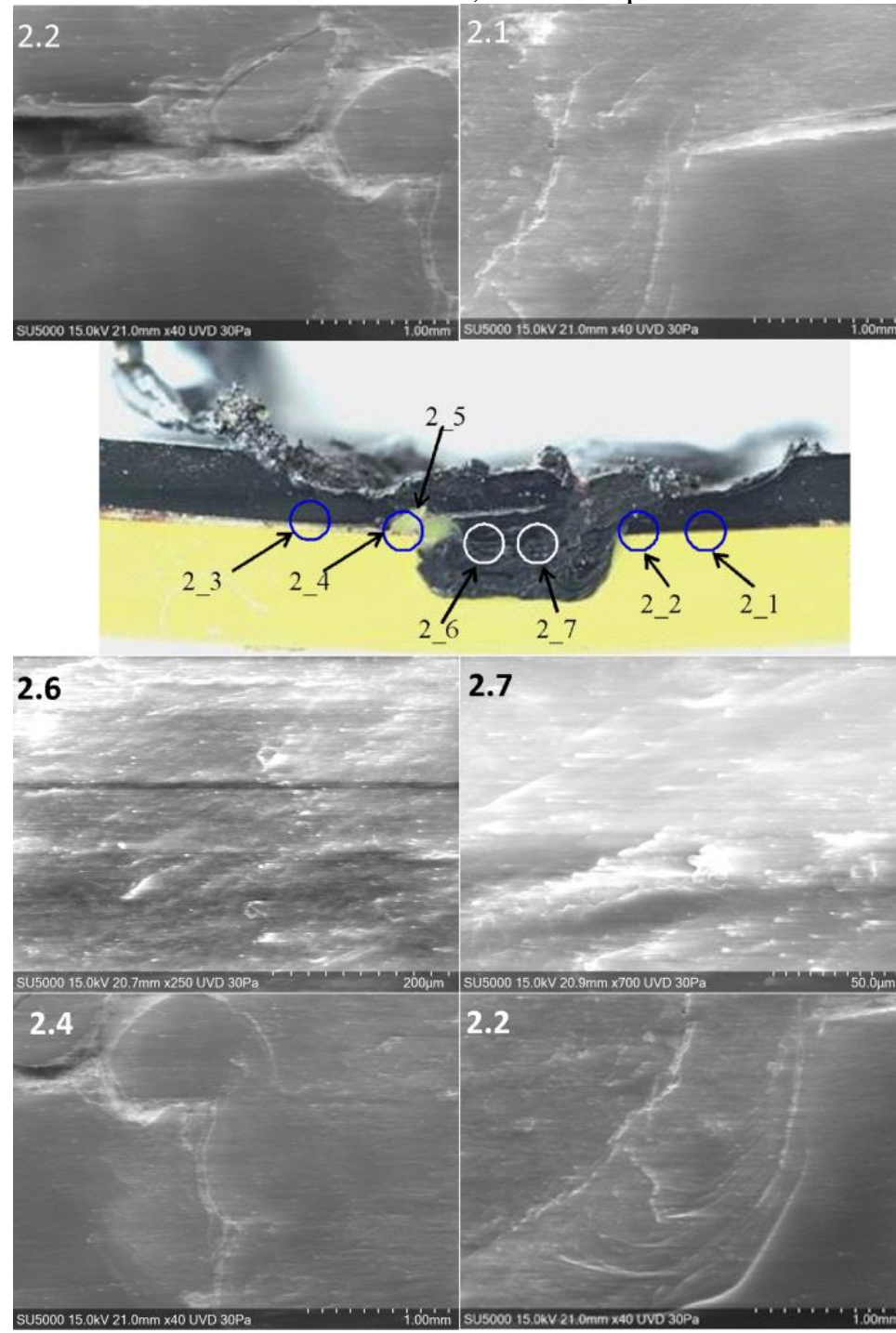

Figure 9. Microstructure in different locations of the black and yellow polyethylene joint 
It is found that:

- in the first case ( $\mathrm{v} 1=40 \mathrm{~mm} / \mathrm{min}$ ), the "trace" of the tool shoulder is not visible, as an effect of its action on the plate located above. The lack of friction between the tool shoulder and the welding material caused the developed temperature of approx. 110-1200C to be insufficient for the formation of the welded joint

- when using the speed of $20 \mathrm{~mm} / \mathrm{min}$ and $30 \mathrm{~mm} / \mathrm{min}$ and at a corresponding pressure of the tool shoulder on the material to be welded (figures 8 ) the formation of the core takes place and implicitly of the welded joint

The morphological analysis of the areas presented in Figure 9 highlights the following aspects:

- the joint area has an irregular shape (the contour of the joint area is highlighted) and there are many "voids" type defects;

- the flow of the material induced by the FSW process is visible.

\section{Conclusions}

Friction Stir Welding has many advantages both in terms of the mechanical properties of the welded material and in terms of energy consumption, which directly leads to lower operating costs. Welding materials by the FSW process is a material joining technique that was originally applied to aluminum alloys, but is now widely used in many industrial applications.

For a proper joint of the polyethylene by FSW technique it is necessary a proper pressure of the tool shoulder on the joint material, as well as the use of speeds of about $30 \mathrm{~mm} / \mathrm{min}$, conditions that lead to the stabilization of the welding process and a uniform appearance of the joint. Otherwise, irregular shapes of the joint and the existence of many "voids" defects were highlighted (on the samples analyzed in this paper).

\section{Acknowledgements}

This work was accomplished within the Partnerships in priority areas - PN II program, implemented with the support of Executive Agency for Higher Education, Research, Development and Innovation Funding (UEFISCDI) and Romanian Ministry of Education and Scientific Research, project no. PN IIPT-PCCA-2013-4-185. All authors are grateful to UEFISCDI for research funding.

\section{References}

[1] Banjare, P. N., Sahlot, P., \& Arora, A. (2017). An assisted heating tool design for FSW of thermoplastics. Journal of Materials Processing Technology, 239, 83-91. doi:10.1016/j.jmatprotec.2016.07.035

[2]. Oliveira, P. H. F., Amancio-Filho, S. T., dos Santos, J. F., \& Hage, E. (2010). Preliminary study on the feasibility of friction spot welding in PMMA. Materials Letters, 64(19), 2098-2101. doi:10.1016/j.matlet.2010.06.050

[3] Kiss, Z., \& Czigany, T. (2012). Microscopic analysis of the morphology of seams in friction stir welded polypropylene. Express Polymer Letters, 6(1), 54-62. doi:10.3144/expresspolymlett.2012.6

[4] Hazim H. Abdulkadhum et al (2020) Mechanical behavior of friction stir welded high-density polyethylene sheets, IOP Conference Series: Materials Science and Engineering, Volume 671, Number 1

[5] P.N. Banjare, P. Sahlot, and A. Arora. (2017) An assisted heating tool design for FSW of thermoplastics." Journal of Materials Processing Technology 239, 83-91.

[6] Simões, F., \& Rodrigues, D. M. (2014). Material flow and thermo-mechanical conditions during Friction Stir Welding of polymers: Literature review, experimental results and empirical analysis. Materials \& Design, 59, 344-351. doi:10.1016/j.matdes.2013.12.038 